as a method of approach to the study of plants, and this holds equally, of course, for all fields of ecology.

The last book of the trio und re review, "Practical Plant Ecology", is by Prof. R. C. MeLean and Dr. Ivimey $\mathrm{Cook}^{3}$ : it gives an account of the field methods and field apparatus which have been found useful in the botanical courses of the University of Cardiff. Its matter-of-fact descriptions of apparatus and technique come down to the level of average students, and will give the means to many hitherto uninstructed folk of gratifying their desire to apply precise measurement to botanical field study. The many examples of records made by students indicate the enthusiasm which the authors have engendered in their classes. There is, of course, a danger that students may record data of temperature, light, or $p \mathrm{H}$, without any comprehension of applicability to the ecological situation being examined; but this can be guarded against by good teaching, and by conjoint use of the "Introduction to Plant Ecology". It is the commencement of careful record and measurement that is for the moment of prime importance, and this book will go far to ensure it. Messrs. Allen and Unwin are to be congratulated upon providing schools and universities with three excellent books, so satisfactorily supplementing each other; it now remains to meet a similar need in the realm of animal ecology, and to show the way to teach the study of the biome, with its complex integration of both plant and animal life.

'Introduction to Plant Ecology : a Guide for Beginners in the Study of Plant Communities. By "A. G. Tansley. Entirely revised and enlarged second edition of "Practical Plant Ecology". Pp. 260.
(London : George Allen and Unwin, Ltd., 1946.) 88. $6 d$. net.

Plant Ecology and the School. By A. G. Tansley and E. Price Evans. Pp. 98. (London: George Allen and Unwin, Ltd., 1946.) 68. net.

?Practical Field Ecology : a Guide for the Botany Departments of Universities, Colleges and Schools. By Dr. R. C. McLean and J.t.., 1946.) 98. net.

\section{SCIENCE AND U.N.E.S.C.O.}

\section{MEETING AT MEXICO CITY}

$\mathrm{I}_{\mathrm{p}}^{\mathrm{N}}$

$\mathrm{N}$ this article we are concerned mainly with the 1 present results from the successful drive to put the 'S' into 'U.N.E.C.O.'. The presence of some thirty scientific men from the thirty-three countries represented at the second general conference of the United Nations Educational, Scientific and Cultural Organisation, held in Mexico City last November, was an earnest that the ' $S$ ' had come to stay; the careful preparations for the programme made by Dr. Joseph Needham and the staff of the Natural Sciences Division and the clear statements made by the representatives of the scientific working party in the plenary sessions account largely for the successful piloting of the various scientific projects past budgetary and other obstacles.

To one accustomed to the atmosphere of international gatherings of scientific men, a first impression of a meeting of the United Nations Educa. tional, Scientific and Cultural Organisation is that, whereas science is truly international in outlook and has learnt to work along international lines, culture is essentially national or racial in outlook and is only just beginning, save on the more mechanical side of museums and libraries, to walk easily along the international path. While the eloquent protest of Sir Sarvepalli Radhakrishnan that the culture of the
East is insufficiently represented on the staff of the Organisation was received with sympathy and applause, speeches which sounded as though they might have been delivered at Lake Success were seen to lie clearly outside the sphere of the Organisation's interests and activities. The temper of the meeting clearly indicated a desire for as complete co-operation as possible: political differences were barred, though in some cases national or racial differences were accepted as playing an inevitable part under present conditions.

The programme of many varied schemes for 1948 put forward in advance of the meeting by the Executive Board called for an all-over budget of $8,500,000$ dollars. As a first step, this was reduced by the full meeting of delegates by 800,000 dollars, so that when the various sectional working parties met to discuss their programmes in detail, they knew approximately the size of the grant that they were likely to receive and they could modify the proposed plans accordingly. The chairman of the working party of the Natural Sciences Division was Dr. H. J. Bhabha. The programme ultimately adopted by this party and accepted by the plenary session included the following items :

(1) Grants in Aid to Non-governmental Organisations (for example, the International Scientific Unions and other bodies of an international character), to meet travelling expenses, publication charges, etc. ; a total of 240,000 dollars was approved.

(2) The Hylean Amazon Scheme. The Organisation is generously supporting in its initial stages the proposal to found an international scientific institute at Belem to study the problems of the great forest zones and the basins drained by the valley of the Amazon. Physical geography, including soil science, biology, anthropology, agriculture and nutrition all provide special problems to be considered. Brazil, as the country most concerned, backs the scheme strongly. It is being supported by the other countries involved in the area-Bolivia, Colombia, Ecuador, Peru, Venezuela and the British, French and Dutch Guianas-also by the United States and at its own request by India, as a country much interested in tropical problems. The Organisation is making a grant of 100,000 dollars in 1948 for initial surveys. Of this sum, 50,000 dollars comes from the money for the Field Science Co-operation Office for Latin America ; Mr. E. J. Corner will be in charge of the initial organisation.

(3) Field Science Co-operation Office. In addition to the Office for Latin America, which is to be assigned for the present to the Hylean Amazon, there already exist two field offices which act as links between the main centres of learning and research and countries remote from such centres. One is at Nanking, serving Far East Asia and the Philippines; the other is at Cairo for the Middle East. The officers in charge are Mr. J. Smid, of Czechoslovakia, and Dr. L. T. Thuriaux, of Belgium, respectively. An additional office for India was agreed to by the conference.

(4) Popularization of Science and of its Social Implications. Following upon two meetings of experts called together in Paris and in New York during October last, the United Nations Educational, Scientific and Cultural Organisation decided to stimulate research and surveys in this field by fellowships, by co-operation with existing bodies working on the subject and by the preparation and circulation of reports. 
The Division of Natural Sciences will also play a part in a number of schemes supported by the Organisation, but having a wide range and affecting other branches of knowledge. These include methods of dealing with rehabilitation in war-devastated countries, exchange of personnel between countries, passage of books across frontiers, documentation, use of mass media for the spread of information, etc. ; as in the case of libraries and museums, men of science are directly concerned in these projects, but only as part of a much wider group of interested people. The same applies to certain aspects of education, which provide the main body of the activities of the Organisation, and call for a separate report in itself.

With regard to the future position of science in the United Nations Educational, Scientific and Cultural Organisation, one fact must be borne in mind. The natural sciences were well organised at the start along intermational lines, while certain other subjects such as the humanities and the social sciences were not. As they fall into line-and the Division for Philosophy and the Humanities has already asked the Organisation to organise a central council along the lines of the International Council of Stientific Unions-they will find useful ways of spending money and will make their appeal to the Organisation for grants. Unless the income of the Organisation rises with its increased opportunities and responsibilities, the grants to science will be maintained at their present level only with difficulty.

In elosing this account, tribute must be paid to the Mexican Government for its gracious welcome and generous hospitality ; the Lebanese Government has been set a hard task for this year's conference at Beirut. This will be the last conference at which Dr. Julian Huxley will hold office as director-general. Dr. Needham retires from the post of head of the Natural Sciences Division this spring. Both of them have placed the scientific men of the world under a debt of obligation by the way they have initiated the scientific section of an organisation which has great possibilities for the future of the civilized world.

F. J. M. S.

\section{THE EARTH'S SURFACE MAGNETIC FIELD AND ITS SECULAR CHANGE}

\section{By Prof. SYDNEY CHAPMAN, F.R.S.}

$\mathrm{T}$

HE Department of Terrestrial Magnetism of the Carnegie Institution of Washington renders a signal service to science by the publication of the important volume entitled 'Description of the Earth's Main Magnetic Field and its Secular Change, 19051945 ". In a sense this represents the attainment (for the time) of one primary objective urged by the first director of the Department, the late L. A. Bauer, upon Andrew Carnegie, in the negotiations which led in 1904 to the institution of the Department. The volume has been prepared almost entirely under the control of the second director, J. A. Fleming, who from early days was Bauer's right-hand man in the development of the Department. The third director is to be congratulated on being able to issue so great a contribution to the science for the furtherance of which his Department was founded.

Bauer set himself with immense zeal to the task of promoting a world magnetic survey more complete than any previously attempted. As most of the earth's surface is water, the chief need was to survey the oceans. Bauer acquired a sailing vessel, the Galilee, for his Department, and adapted it (adding auxiliary engines) for magnetic survey work, on which it made three cruises. A non-magnetic vessel, the Carnegie, was then specially constructed, which made seven great survey cruises before it was over. taken by the disaster of destruction by fire in the harbour of Apia, Samoa, in 1929. These cruises form the main basis of our knowledge of the earth's surface magnetic field to-day, though supplemented by information provided by the land magnetic surveys undertaken by the principal civilized States in their own or dependent territories, and by the work of many polar and other expeditions.

Since 1929 our knowledge of the earth's magnetism has been slowly worsening. The outbreak of war halted the completion and equipment of the Royal Research Ship Research, a non-magnetic vessel built by the British Admiralty to resume the ocean magnetic survey work so well executed by the Carnegie during two decades. The fate of the Research is at present in doubt, but it may be hoped that the ship will soon begin her work and help to renew our current knowledge of the earth's ever-changing magnetic state.

Although Bauer intended to make a thorough theoretical study of the magnetic data obtained by his survey ships and by the land magnetic expeditions he organised or aided, along with all other available data, he actually made only slight progress in this work. But with generous wisdom he made his data quickly available for use in the construction of magnetic charts by the principal national agencies responsible for producing such charts. In particular, the early work of the Galilee and Carnegie formed the basis of the Admiralty charts when their preparation was transferred in 1917 to the Royal Observatory, Greenwich.

The supervision of this work by the then Astronomer Royal, the late Sir Frank Dyson, enhanced his interest in geomagnetism and led him, with $H$. Furner, to make an excellent spherical harmonic analysis of the earth's field for the epoch 1922-the only thorough analysis made during a considerable period extending before and after 1922 .

The subsequent further accumulation of magnetic data enhanced the need for further study of the worldwide distribution and secular change of the field. A valuable beginning of this work was made in 1930 by $H$. W. Fisk (of the Department of Terrestrial Magnetism, Carnegie Institution), by his isoporic charts showing for each magnetic element the lines (isopors) of equal rate of secular change. The Department's plans for a more comprehensive treatment of this century's store of magnetic data first began to mature rapidly when, during the War, the work became the subject of a Government contract under the United States Naval Department. It was entrusted to a team of members of the staff of the Department of Terrestrial Magnetism, under the able leadership of E. H. Vestine, and has been executed thoroughly and successfully. The volume now under notice is the first fruits, and is to be followed by others giving a new spherical harmonic analysis of the field, and other developments.

The main contents of the volume indicate (i) the state of the earth's surface magnetic field for the epoch $1945 \cdot 0$, and (ii) the rate of change of the field at each of the four epochs $1912 \cdot 5,1922 \cdot 5,1932 \cdot 5$ and $1942 \cdot 5$. The field can be specified at any point by 